\title{
Photoinduced Charge Transfer and Bimetallic Bond Dissociation of a Bi-W Complex in Solution
}

Sean A. Boulanger, Liangdong Zhu, Longteng Tang, Sumit Saha, Douglas A. Keszler, and Chong Fang*

Department of Chemistry, Oregon State University, 153 Gilbert Hall, Corvallis, Oregon 973314003, United States

*To whom correspondence may be addressed. Email: Chong.Fang@oregonstate.edu 


\section{SI Text}

Experimental Materials and Methods

\section{SI Figures}

Figure S1. Steady-state electronic absorption spectra of $\mathrm{Ph}_{3} \mathrm{Bi}$ and $\mathrm{W}(\mathrm{CO})_{6}$ in $\mathrm{MeOH} \quad \mathrm{S} 6$

Figure S2. Calculated electronic absorption spectrum of $\mathrm{Bi}-\mathrm{W}$ in $\mathrm{MeOH} \quad \mathrm{S} 7$

Figure S3. Time-dependent electronic absorption spectrum of $\mathrm{Bi}-\mathrm{W}$ in $\mathrm{MeOH}$ under UV $\begin{array}{ll}\text { lamp irradiation } & \text { S8 }\end{array}$

Figure S4. The role of the trans ligand in $\mathrm{W}-\mathrm{CO}$ (axial) $\pi$-backbonding determined by quantum calculations

Figure S5. Probe-dependent TA dynamics of $\mathrm{W}(\mathrm{CO})_{6}$ in $\mathrm{MeOH}$ and $\mathrm{Bi}-\mathrm{W}$ in $\mathrm{MeOH}$ or EtOH after $280 \mathrm{~nm}$ laser excitation S10-11

Additional discussions follow each figure.

\section{SI Tables}

Table S1. Ground state Raman mode assignments for $\mathrm{W}(\mathrm{CO})_{6}, \mathrm{~W}(\mathrm{CO})_{5}-\mathrm{Bi}(\mathrm{Ph})_{3}$, and $\mathrm{W}(\mathrm{CO})_{5}-\left(\mathrm{OHCH}_{3}\right)$ in $\mathrm{MeOH}$ S12-13

Table S2. Selected bond lengths for $\mathrm{W}(\mathrm{CO})_{5}-\mathrm{Bi}(\mathrm{Ph})_{3}$ predicted by DFT calculations with different functionals in comparison to experimental values

Table S3. Calculated bond lengths for $\mathrm{W}$-Ligand (trans) $\left(\mathrm{L}=\mathrm{CO}, \mathrm{Bi}(\mathrm{Ph})_{3}\right.$, and $\left.\mathrm{OHCH}_{3}\right)$ and $\mathrm{W}-\mathrm{CO}$ (axial) in the tungsten carbonyl complex 


\section{$\underline{\text { SI Text }}$}

\section{Experimental Materials and Methods:}

Sample preparation. Tungsten hexacarbonyl $\mathrm{W}(\mathrm{CO})_{6}$ with $>99 \%$ purity was purchased from Strem Chemicals, Inc. Triphenylbismuth $\mathrm{Ph}_{3} \mathrm{Bi}$ with $>99 \%$ purity was purchased from Alfa Aesar. Both chemical compounds were used without further purification. Triphenylbismuth-tungsten pentacarbonyl complex $\mathrm{Ph}_{3} \mathrm{Bi}-\mathrm{W}(\mathrm{CO})_{5}$ (abbreviated as $\mathrm{Bi}-\mathrm{W}$ here) was synthesized as previously reported by Holmes et al.; these details can be found elsewhere. ${ }^{1,2}$ The lab-grade solvent pure anhydrous ethanol (EtOH) was purchased from Koptec, and the high performance liquid chromatography (HPLC)-grade methanol (MeOH) was purchased from EMD Millipore Corporation. Both solvents were dried by standard procedures and freshly distilled prior to use. The experiments were conducted at atmospheric pressure $(1 \mathrm{~atm})$ and room temperature $\left(22{ }^{\circ} \mathrm{C}\right)$.

Steady-state electronic spectroscopy. The steady-state absorbance measurements of W(CO) ${ }_{6}$ and $\mathrm{Bi}-\mathrm{W}$ in solution were conducted before and after ultraviolet (UV) exposure with a Thermo Scientific Evolution 201 UV/Visible (UV/Vis) spectrophotometer with a 1-mm-pathlength quartz cuvette (Spectrosil 1-Q-1, Starna Cells). The UV radiation source came from either a femtosecond (fs) laser (described below) or a continuous-wave (cw) lamp. The cw irradiation was performed using an unfocused 4-watt 254/365 nm UVGL-25 Compact UV Lamp (UVP). The short wave (254 nm) setting with a power of $\sim 0.2 \mathrm{~mW}$ was used in these experiments.

Time-resolved electronic and ground-state stimulated Raman spectroscopy. For molecular characterization, both the femtosecond stimulated Raman spectra (FSRS) in the electronic ground state (GS, $\mathrm{S}_{0}$ ) and transient absorption (TA) data involving the excited states (e.g., $\mathrm{S}_{1}$ ) were taken from the home-built optical setups that are based on a femtosecond Ti:sapphire laser regenerative amplifier system (Legend Elite-USP-1K-HE, Coherent, Inc.), seeded by a mode-locked 
Ti:sapphire oscillator (Mantis-5, Coherent, Inc.). The fundamental laser output pulse train is at $\sim 800 \mathrm{~nm}$ center wavelength, $\sim 35 \mathrm{fs}$ pulse duration, $\sim 4 \mathrm{~mJ}$ pulse energy, and $1 \mathrm{kHz}$ repetition rate. ${ }^{3}$

The supercontinuum white light (SCWL) is used as the broadband probe pulse in both the fsTA and GS-FSRS experiments, which is generated by focusing a small portion of fundamental laser pulse onto a 2-mm-thick quartz cuvette (Spectrosil 1-Q-2, Starna Cells) filled with deionized water. The SCWL is compressed via a chirped mirror pair (DCM-12, 400-700 nm, Laser Quantum, Inc.) to $<100$ fs full-width-at-half-maximum (FWHM) of the pulse temporal profile. ${ }^{4}$

The generation of a picosecond (ps) narrow bandwidth Raman pump pulse requires a second harmonic bandwidth compressor (SHBC) with $\sim 150 \mu \mathrm{J} /$ pulse output at $400 \mathrm{~nm}$ and a picosecond wavelength-tunable seed pulse. ${ }^{5}$ Through the two-stage noncollinear parametric amplification (NOPA) with suitable BBO crystals, the seed pulse was then amplified by the $400 \mathrm{~nm}$ pump from SHBC on the ps timescale to achieve a $510 \mathrm{~nm}$ Raman pump with $\sim 2 \mu \mathrm{J}$ pulse energy.

The fs photoexcitation pulse in TA experiments was set to match the sample absorption peak at $\sim 280 \mathrm{~nm}$ (see Figure 1), which originated from the second harmonic generation of a two-stage home-built fs-NOPA output at $560 \mathrm{~nm}$. The energy of this UV excitation pulse is set at $\sim 0.3 \mu \mathrm{J}$. The instrument response function was measured via the cross-correlation time between the fs pump and probe pulses in methanol housed in the 1-mm-pathlength quartz cuvette to be $\sim 140 \mathrm{fs}^{6}$

The incident Raman pump/TA pump and probe beams were focused by a parabolic reflective mirror $(R F L=101.6 \mathrm{~mm}$, MPD249-F01, Thorlabs, Inc.) onto the solution sample housed in a 1mm-thick quartz cuvette. ${ }^{4,7}$ A miniature magnetic stir bar was used to minimize the UV-lightinduced sample degradation. ${ }^{8}$ The transmitted probe was collimated and focused into an imaging spectrograph (Acton SpectraPro SP-2356, Princeton Instruments, Inc.) and collected via a frontilluminated CCD array camera with Lumogen coating (PIXIS:100F, Princeton Instruments, Inc.). 
Quantum calculations. The $\mathrm{S}_{0}$ Raman mode frequencies of $\mathrm{W}(\mathrm{CO})_{6}, \mathrm{Bi}-\mathrm{W}$, and $\mathrm{W}(\mathrm{CO})_{5}-$ $\left(\mathrm{OHCH}_{3}\right)$ in $\mathrm{MeOH}$ were calculated using the density functional theory (DFT) method with the $\omega \mathrm{B} 97 \mathrm{X}-\mathrm{D}$ functional and the Genecp mixed basis sets of the geometrically optimized Bi-W structure using Gaussian 09 software. ${ }^{9}$ The metal centers were calculated with the LANL2DZ basis set and the organic atoms were calculated with the $6-31 \mathrm{G}(\mathrm{d}, \mathrm{p})$ basis set. ${ }^{10}$ The solvent $\mathrm{MeOH}$ was modeled using the integral equation formalism variant polarizable continuum model (IEFPCM), except the explicit methanol molecule that occupies the vacant axial site of the pentacarbonyl species after the photochemical reaction (i.e., forming the $\mathrm{W}(\mathrm{CO})_{5}-\left(\mathrm{OHCH}_{3}\right)$ complex). The calculated vibrational normal mode frequencies have a scaling factor of 1.00 for this level of theory. ${ }^{11,12}$ The vertical absorption spectra (see Figure S2 below) and frontier molecular orbitals of the electron density distribution (Figure 4 in main text) were retrieved from the time-dependent (TD)-DFT energy calculations at the optimized geometry of the electronic ground state using the same functional and basis sets. The first 20 excited states were calculated and the set UV/Vis peak FWHM is $\sim 0.67 \mathrm{eV}$. However, the attempted TD-DFT geometric optimization calculations were unsuccessful, likely due to the swift $\mathrm{Bi}-\mathrm{W}$ bond dissociation in the electronic excited state.

The range-separated $\omega$ B97X-D functional has been often chosen for dissociation and chargetransfer systems due to its inclusion of long-range corrections (free of long-range self-interaction) to better model the molecular complexes of interest including cocrystal structures (e.g., involving a halogen donor and $\mathrm{Ph}_{3} \mathrm{Bi}$ as a putative acceptor). ${ }^{13,14}$ Here, the 6-31G(d,p) basis set for organic atoms was deemed sufficient since the $\omega$ B97X-D functional accounts for diffusive interactions and the results closely match experimental values. Unlike B3LYP that overestimates metalcarbonyl and metal-metal bond lengths, ${ }^{15}$ the results from $\omega$ B97X-D calculations are in better agreement with the Bi-W crystal structure bond lengths (see Table S2 below). ${ }^{1}$ 


\section{$\underline{\text { SI Figures }}$}

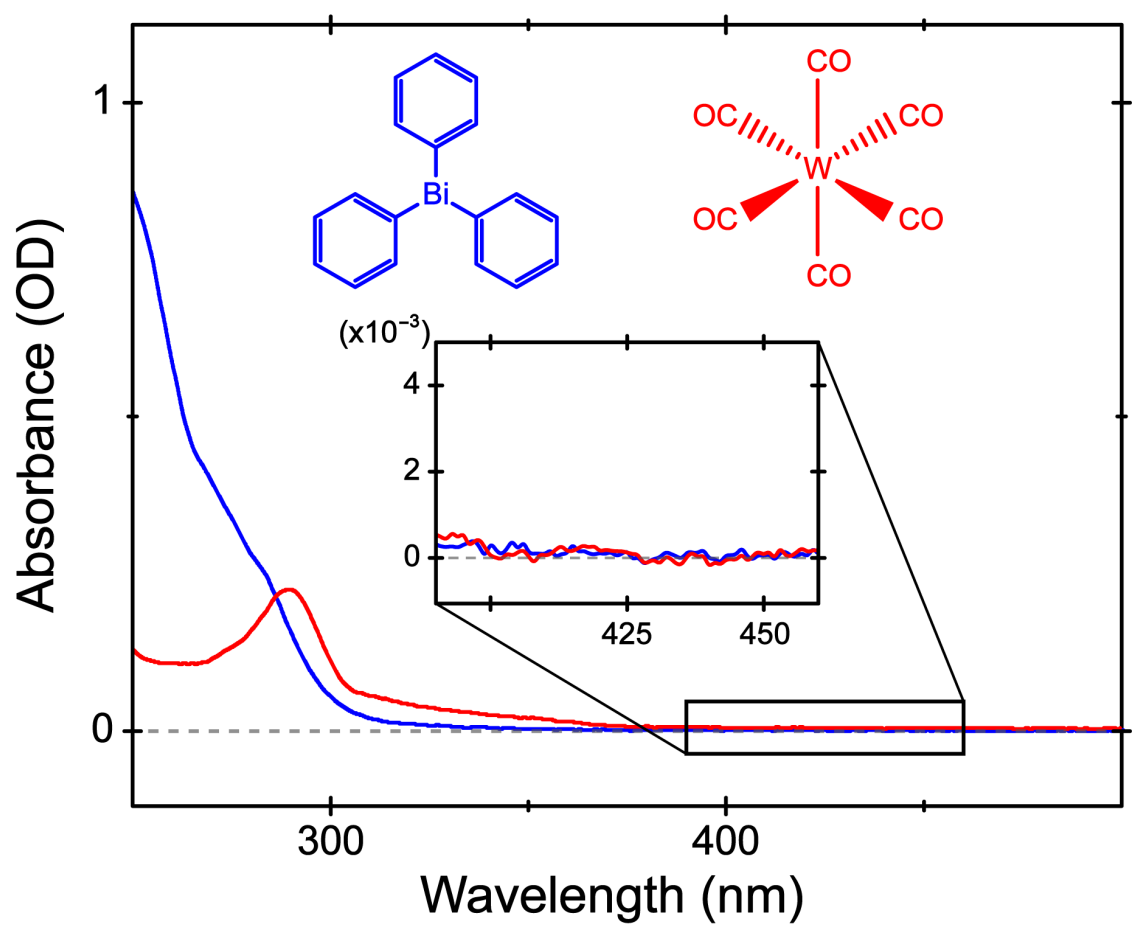

Figure S1. Chemical structures and steady-state electronic absorption spectra of the unirradiated $\sim 0.2 \mathrm{mM} \mathrm{Ph}_{3} \mathrm{Bi}$ (blue) and $\mathrm{W}(\mathrm{CO})_{6}$ (red) in methanol. The enlarged spectral region (inset) highlights no notable absorption around $419 \mathrm{~nm}$.

As described in main text, tungsten pentacarbonyl species typically have an absorption band around $420 \mathrm{~nm} \cdot{ }^{8,16-19}$ These measurements corroborate that the peak at 419 (416) nm in the Bi-W complex in $\mathrm{MeOH}(\mathrm{EtOH})$ before UV excitation (see Figure 1b,c in main text) is likely due to the presence of some $\mathrm{W}(\mathrm{CO})_{5}-$ solvent complexes, since there is no notable absorption in this spectral region due to either $\mathrm{Ph}_{3} \mathrm{Bi}$ or $\mathrm{W}(\mathrm{CO})_{6}$ in $\mathrm{MeOH}$. Furthermore, the $\mathrm{Bi}-\mathrm{W}$ complex represents a tungsten pentacarbonyl species as well, just the sixth ligand is $\mathrm{Ph}_{3} \mathrm{Bi}$ instead of a solvent molecule. Therefore, the observed absorption peak increase around $419 \mathrm{~nm}$ in Figure 1b,c may also indicate that the $\mathrm{W}(\mathrm{CO})_{5}-$ solvent complex has a higher extinction coefficient than the $\mathrm{Bi}-\mathrm{W}$ complex. 


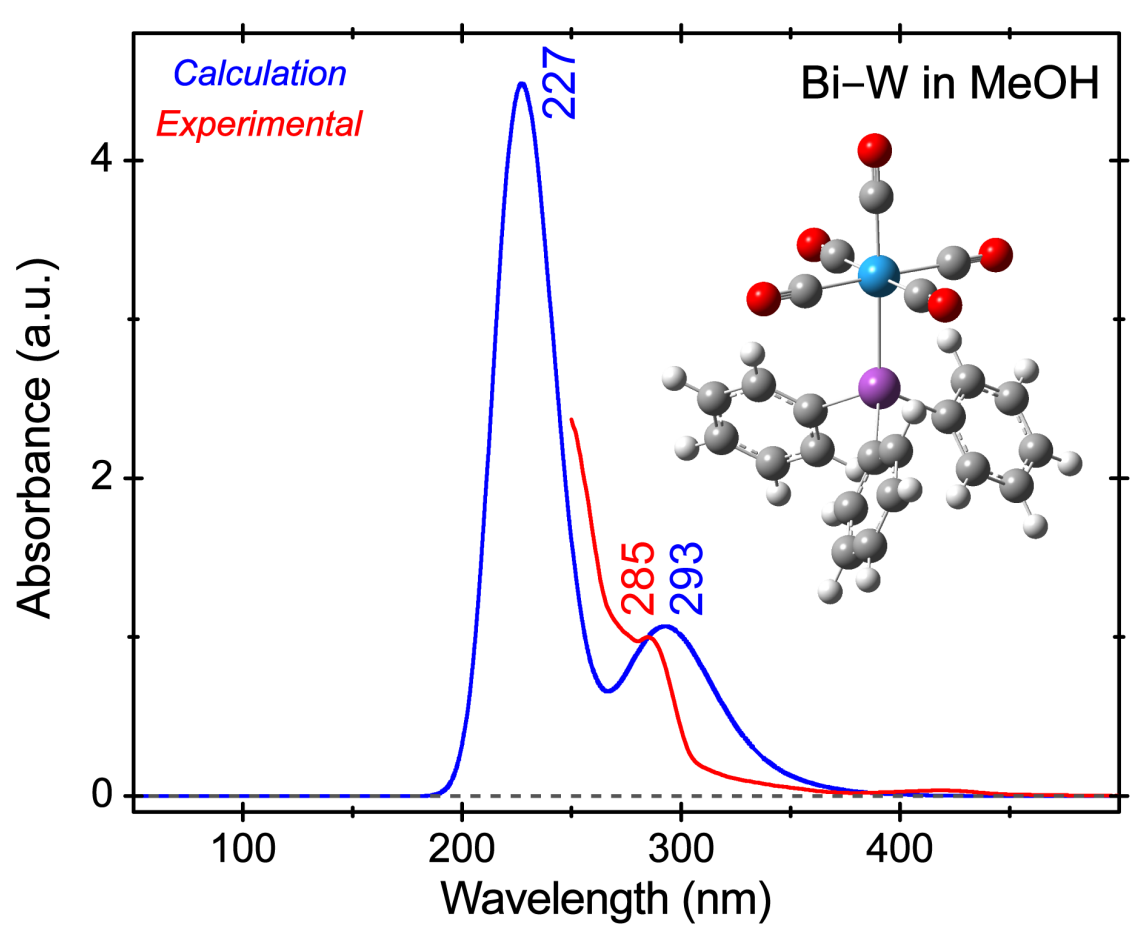

Figure S2. Steady-state electronic absorption spectrum of $\mathrm{Bi}-\mathrm{W}$ in $\mathrm{MeOH}$ from the TD-DFT energy calculation at the geometrically optimized structure from the ground-state DFT calculation (blue) and experiment (red). The scaling factor for the calculated spectrum is $\times 10^{-4}$.

The calculated absorption spectrum of $\mathrm{Bi}-\mathrm{W}$ in $\mathrm{MeOH}$ (details described above) shows an intense band centered at $227 \mathrm{~nm}$ that involves more of the $\sigma \rightarrow \sigma^{*}$ electronic transition. It is important to know the relative position of this band since this transition is typically responsible for $\mathrm{M}-\mathrm{M}$ bond dissociation. ${ }^{20,21}$ For the experimentally observed electronic absorption band at 285 $\mathrm{nm}$, the calculated $\mathrm{HOMO} \rightarrow \mathrm{LUMO}+1$ transition (rather than the HOMO $\rightarrow$ LUMO transition) is the main contributor (see Figure 4a for the pertinent electronic density distribution). Since the actinic pump for our fs-TA experiments at $280 \mathrm{~nm}$ does not directly overlap with the $\sigma \rightarrow \sigma^{*}$ band, we could excite $\mathrm{Bi}-\mathrm{W}$ into a charge-transfer band (see Figure 4 in main text) that may facilitate the bimetallic bond dissociation of this complex in solution as the main interest of this work. ${ }^{22}$ 


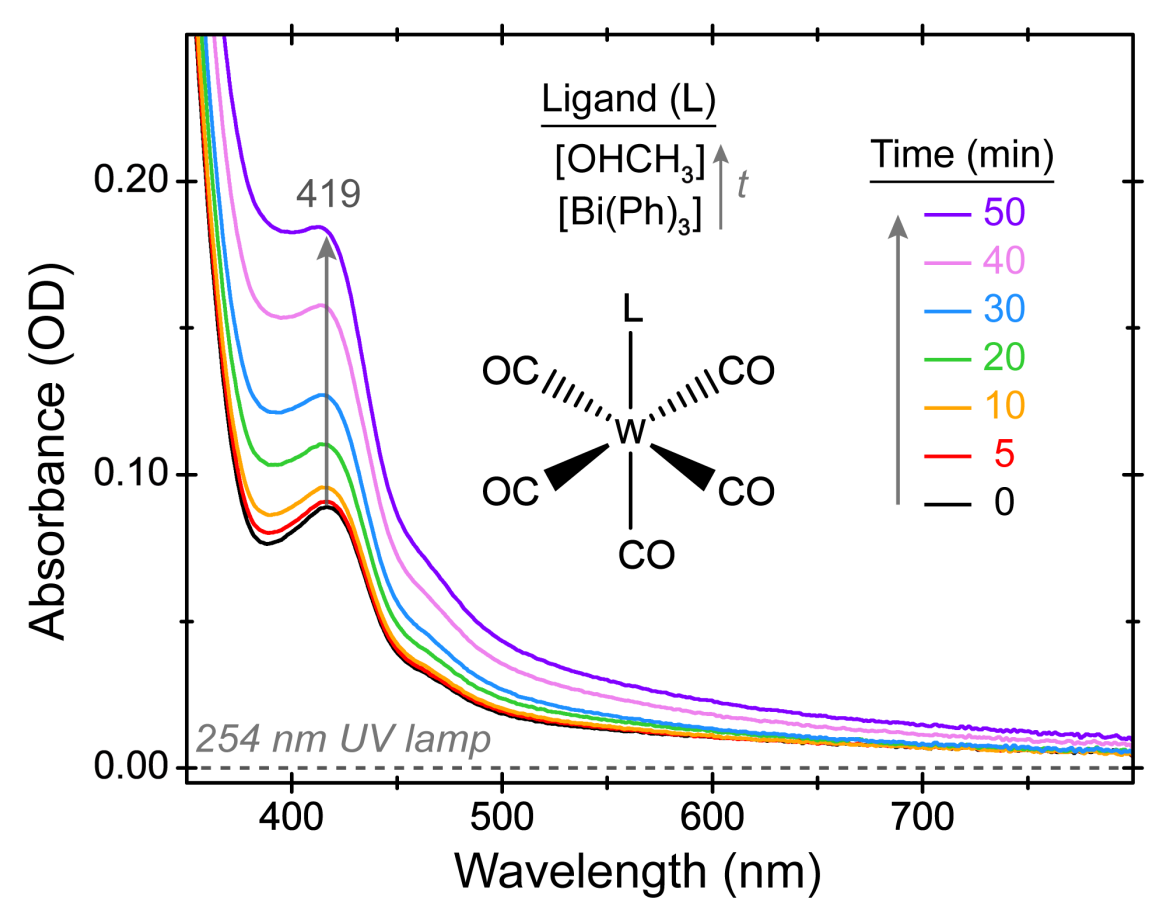

Figure S3. Time-dependent electronic absorption spectra of $5 \mathrm{mM} \mathrm{Bi}-\mathrm{W}$ in $\mathrm{MeOH}$ under $254 \mathrm{~nm}$ UV lamp irradiation ( $\sim 0.2 \mathrm{~mW}$ power at the sample spot) from 0 to 50 minutes. Time progression is indicated by the gray arrow. The tungsten pentacarbonyl species with two different axial ligands (L) are depicted in the inset.

The time-dependent absorption spectra of $\mathrm{Bi}-\mathrm{W}$ in $\mathrm{MeOH}$ were taken to determine the time necessary to efficiently convert the $\mathrm{Bi}-\mathrm{W}$ complex to the $\mathrm{W}(\mathrm{CO})_{5}-\left(\mathrm{OHCH}_{3}\right)$ photoproduct (see main text). Due to the significantly raised baseline from graphitic carbon and crystalline bismuth accumulation (in solution as well as on the inner side of the laser-incident surface) and scattering after $\sim 30$ minutes of UV lamp irradiation, ${ }^{23}$ the GS-FSRS spectra were collected before and after 30 minutes of UV exposure to characterize the two species (reactant and product) in Figure $2 b^{7,8}$ 

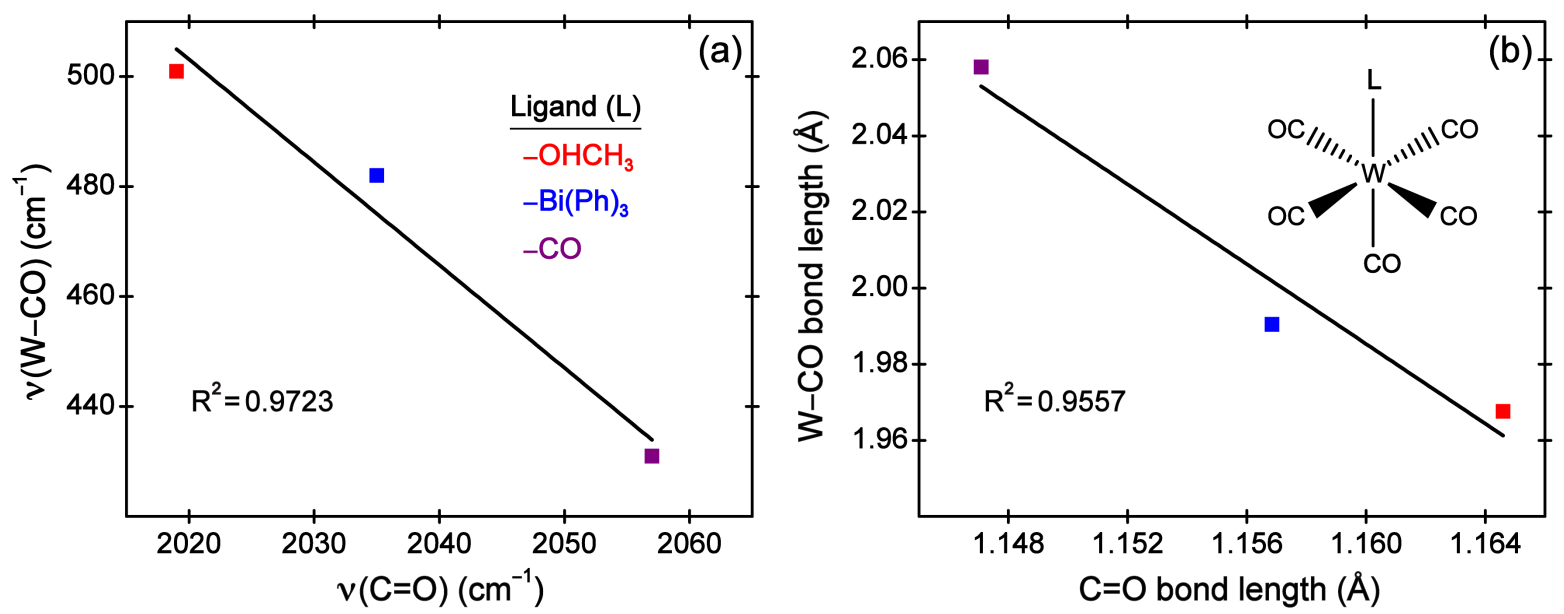

Figure S4. Plot of the $\mathrm{W}(\mathrm{CO})_{5}-\mathrm{L}$ complexes in $\mathrm{MeOH}$ from DFT geometric optimization and frequency calculations of (a) $v(\mathrm{~W}-\mathrm{CO})$ vs. $v(\mathrm{C}=\mathrm{O})$ frequencies, and (b) $\mathrm{W}-\mathrm{CO} v \mathrm{vs} . \mathrm{C}=\mathrm{O}$ bond lengths, where the CO ligand selectively plotted is in the axial position. Data points are shown as the color-coded squares according to the ligand (L): $\mathrm{MeOH}$ (red), $\mathrm{Ph}_{3} \mathrm{Bi}$ (blue), and $\mathrm{CO}$ (violet). The calculated vibrational normal mode frequencies in panel (a) can be found in Table S1 below. The least-squares linear fits are shown in black and the $\mathrm{R}^{2}$ values are displayed in the inset.

The role of the trans ligand in $\mathrm{W}-\mathrm{CO}$ (axial) $\pi$-backbonding was determined by DFT calculations. The stronger electron-donating ligand corresponds to a shorter $\mathrm{W}-\mathrm{C}$ bond length due to the increased electron density on the metal center, which increases the $\pi$-backbonding from the central metal $(\mathrm{W}) \mathrm{d}$ orbital to the coordinating ligand $(\mathrm{CO}) \pi^{*}$ orbital and thus the axial $\mathrm{C}=\mathrm{O}$ bond length (i.e., reducing the bond order). ${ }^{16}$ The longer bond leads to a decreased stretching frequency, and vice versa. From the plots above, the electron-donating ability of the trans ligand increases in the following order: $\mathrm{CO}<\mathrm{Bi}(\mathrm{Ph})_{3}<\mathrm{OHCH}_{3}$, and the calculated axial $\mathrm{W}-\mathrm{CO} / \mathrm{C}=\mathrm{O}$ stretching frequencies are 431/2057, 482/2035, and 501/2019 $\mathrm{cm}^{-1}$, respectively (see Table S1). In tandem, the calculated axial W-CO bond lengths are 2.06, 1.99, and $1.97 \AA$ (see Table S3). 


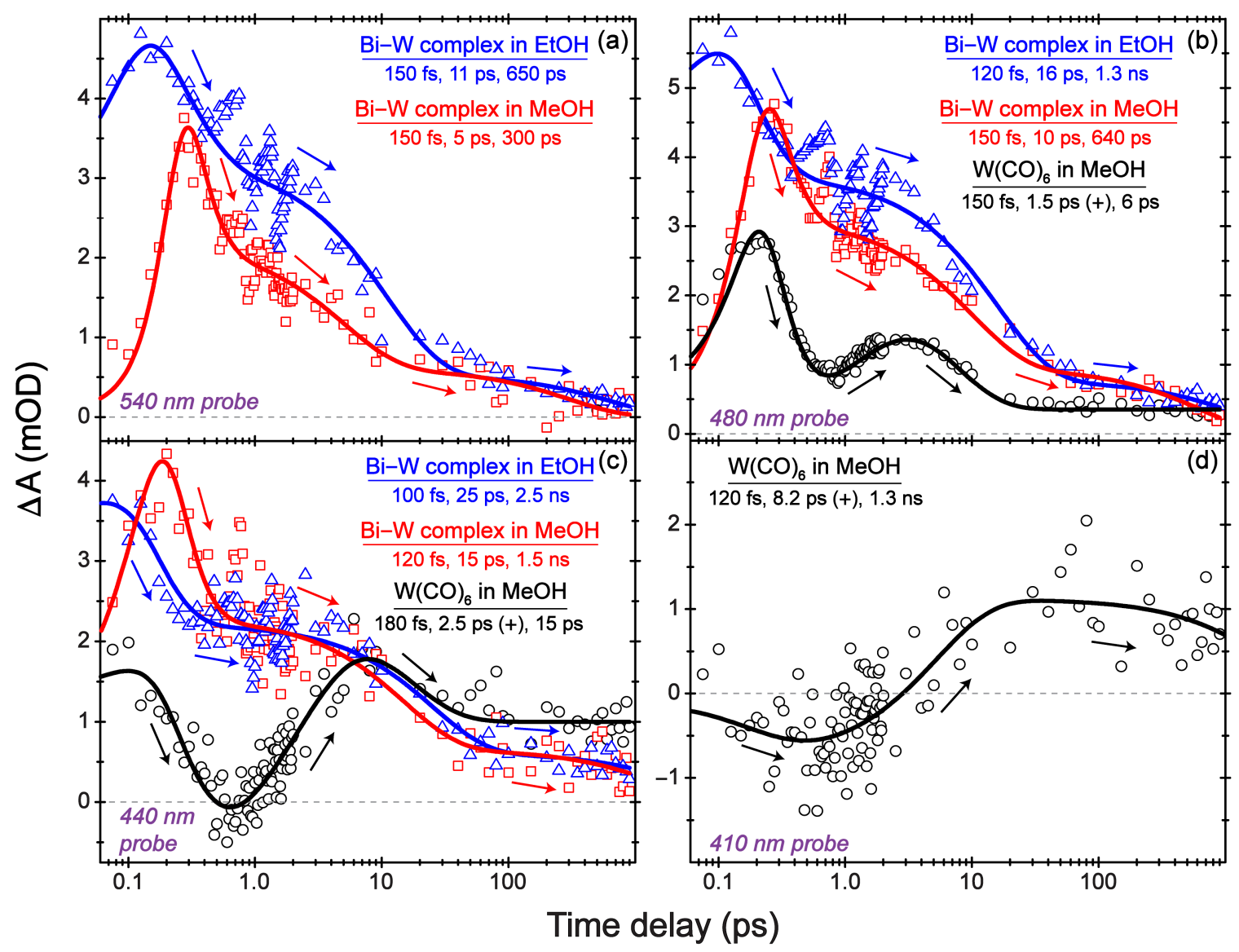

Figure S5. The semilogarithmic plot of the integrated intensity of transient electronic bands from the fs-TA spectra of $\mathrm{W}(\mathrm{CO})_{6}$ in $\mathrm{MeOH}$ (black), $\mathrm{Bi}-\mathrm{W}$ in $\mathrm{MeOH}$ (red), and $\mathrm{Bi}-\mathrm{W}$ in $\mathrm{EtOH}$ (blue) upon $280 \mathrm{~nm}$ excitation at (a) $540 \mathrm{~nm}$, (b) $480 \mathrm{~nm}$, (c) $440 \mathrm{~nm}$, and (d) $410 \mathrm{~nm}$ probe wavelengths. The triexponential least-square fits of the integrated peak intensity dynamics are shown as the color-coded solid curves overlaid with data points (hollow circles, squares, or triangles). The time constants for each system are listed, respectively, and the $(+)$ sign denotes a rise component.

The fs-TA dynamics across various probe wavelengths reveal the electronic excited-state reaction coordinates ${ }^{7,8,24}$ that track the molecular events leading up to the $\mathrm{W}(\mathrm{CO})_{5}$-solvent photoproduct formation and relaxation. Apart from the initial decay on the $\sim 150 \mathrm{fs}$ timescale, the temporal components lengthen as the bluer probe wavelength is chosen toward the photoproduct, providing insights into the non-equilibrium potential energy surface (see Scheme 1 in main text). 
With alcohol solutions, it was proposed that either the hydroxyl or alkyl moieties of the solvent molecules may initially coordinate to the vacant site of the tungsten pentacarbonyl species. ${ }^{19,25,26}$ However, the $\mathrm{W}-\mathrm{O}$ bond is more thermodynamically stable than the $\mathrm{W}-\mathrm{C}$ bond, hence the alkylcoordinated species may undergo conformational rearrangement on the hundreds of ps timescale in the long-chain alcohols (e.g., propanol and above) to form the hydroxyl-coordinated species. ${ }^{27}$ In essence, due to the small size of $\mathrm{MeOH}$ and $\mathrm{EtOH}$ molecules (vs. long-chain alcohols), the very limited alkyl sites for metal coordination (see Figure 1 insets for illustration), as well as the fast longitudinal relaxation time (solvent molecular reorientation on the $10-20 \mathrm{ps}$ timescale), ${ }^{28-30}$ these two alcoholic solvents used in this work enable a clear experimental observation of ultrafast solvation events after photoexcitation to reach primarily the hydroxyl-coordinated species with the characteristic excited-state absorption (ESA) band blueshift (see Figure 3 and Figure S5 above). ${ }^{8,19}$

Notably, due to current limitations of the detection window on the blue side (e.g., no probe photons below $\sim 420 \mathrm{~nm}$ in Figure 3), there is no direct evidence from our fs-TA data that could lead to an accurate assignment of geminate recombination by monitoring the ultrafast recovery of the ground-state bleaching (GSB) signal. ${ }^{31,32}$ Adding a fourth component to the global analysis fit in Figure $3 \mathrm{~b}$ had no significance towards unveiling this phenomenon; a bluer probe region on the femtosecond to picosecond timescales could provide additional insights. ${ }^{21,32}$ Detailed analysis of the collection-set-dependent TA spectra of $\mathrm{W}(\mathrm{CO})_{6}$ in methanol revealed a gradual increase of the $\sim 426 \mathrm{~nm}$ negative peak magnitude (Figure 3a), suggesting that more $\mathrm{W}(\mathrm{CO})_{5}-$-solvent species form on the minute to hour timescale after UV photoexcitation so the associated GSB dynamics could show up in the averaged spectra from six datasets that were typically collected. In contrast, such a negative dip is absent in the fs-TA spectra of $\mathrm{Bi}-\mathrm{W}$ complexes in solution (Figure 3c,e), likely due to a stronger ESA band in the visible region and much less geminate recombination (main text). 


\section{SI Tables}

Table S1. Experimental Raman mode frequencies and assignments aided by quantum calculations

\begin{tabular}{|c|c|c|c|c|c|c|}
\hline \multirow[t]{2}{*}{ Raman mode assignment $^{a}$} & \multicolumn{2}{|c|}{$\mathrm{W}(\mathrm{CO})_{6}$} & \multicolumn{2}{|c|}{$\begin{array}{l}\mathrm{W}(\mathrm{CO})_{5-} \\
\mathrm{Bi}(\mathbf{P h})_{3}\end{array}$} & \multicolumn{2}{|c|}{$\begin{array}{c}\mathrm{W}(\mathrm{CO})_{5}^{-} \\
\left(\mathrm{OHCH}_{3}\right)^{\&} \\
\mathrm{Bi}_{(\mathrm{Ph})_{3}}{ }^{e}\end{array}$} \\
\hline & exp. $^{b}$ & cal. ${ }^{c, d}$ & exp. $^{b}$ & cal. ${ }^{c, d}$ & exp. $^{b}$ & cal. ${ }^{c, d}$ \\
\hline $\begin{array}{l}\text { in-plane }{ }^{f} \text { four } \mathrm{W}-\mathrm{C} \\
\text { antisymmetric stretch }\end{array}$ & 380 & 407 & \multicolumn{2}{|c|}{ N/A } & 411 & 420 \\
\hline $\begin{array}{c}\text { three } \mathrm{W}-\mathrm{C}=\mathrm{O} \text { bending } \\
\text { motions }\end{array}$ & \multicolumn{2}{|c|}{ N/A } & 411 & 420 & \multicolumn{2}{|c|}{ N/A } \\
\hline $\begin{array}{l}\text { W-C symmetric stretch, } \\
\text { molecular breathing }\end{array}$ & 434 & 431 & \multicolumn{4}{|c|}{ N/A } \\
\hline $\begin{array}{c}\text { in-plane }^{f} \text { four } \mathrm{W}-\mathrm{C} \\
\text { symmetric stretch, } \\
\text { antisymmetric axial } \mathrm{W}-\mathrm{C} \\
\text { stretch }\end{array}$ & \multicolumn{2}{|c|}{ N/A } & 434 & 438 & 434 & 433 \\
\hline $\begin{array}{l}\text { axial } \mathrm{W}-\mathrm{C} \text { stretch, in-plane } \\
\mathrm{W}-\mathrm{C}=\mathrm{O} \text { deformation }\end{array}$ & \multicolumn{2}{|c|}{ N/A } & 470 & 482 & 478 & 501 \\
\hline $\begin{array}{c}\mathrm{W}-\mathrm{C}=\mathrm{O} \text { deformation, } \mathrm{C}-\mathrm{W}- \\
\mathrm{C} \text { bend }\end{array}$ & 486 & 498 & \multicolumn{4}{|c|}{ N/A } \\
\hline $\begin{array}{l}\text { five } \mathrm{W}-\mathrm{C}=\mathrm{O} \text { bending } \\
\text { motions, } \mathrm{C}-\mathrm{W}-\mathrm{C} \text { bend }\end{array}$ & \multicolumn{2}{|c|}{ N/A } & 534 & 552 & 572 & 573 \\
\hline benzene ring deformation $^{h}$ & \multicolumn{2}{|c|}{ N/A } & 648 & 678 & 648 & 670 \\
\hline benzene ring $\mathrm{C}=\mathrm{C}$ stretch $^{h}$ & \multicolumn{2}{|c|}{ N/A } & 1680 & 1670 & 1728 & 1671 \\
\hline $\begin{array}{c}\text { axial two } \mathrm{C}=\mathrm{O} \text { antisymmetric } \\
\text { stretch }^{i}\end{array}$ & 1983 & 2057 & \multicolumn{4}{|c|}{ N/A } \\
\hline $\begin{array}{l}\text { in-plane }{ }^{f} \text { two } \mathrm{C}=\mathrm{O} \\
\text { antisymmetric stretch, axial } \\
\mathrm{C}=\mathrm{O} \text { stretch }^{i}\end{array}$ & \multicolumn{2}{|c|}{ N/A } & 2030 & 2035 & 2030 & 2019 \\
\hline $\begin{array}{l}\text { in-plane }{ }^{f} \text { four } \mathrm{C}=\mathrm{O} \\
\text { antisymmetric stretch }\end{array}$ & 2030 & 2010 & 2137 & 2092 & 2145 & 2086 \\
\hline five $\mathrm{C}=\mathrm{O}$ symmetric stretch & \multicolumn{2}{|c|}{ N/A } & 2189 & 2188 & 2204 & 2192 \\
\hline $\begin{array}{c}\text { all six } \mathrm{C}=\mathrm{O} \text { symmetric } \\
\text { stretch }^{g}\end{array}$ & 2136 & 2233 & \multicolumn{4}{|c|}{$\mathrm{N} / \mathrm{A}$} \\
\hline
\end{tabular}

${ }^{a}$ The Raman mode assignment of major atomic motions aided by quantum calculations. The predicted vibrational frequency trends and intensities are the main focusing points since our 
calculations did not account for Jahn-Teller effects or other equilibrium molecular distortions that are typically expected in metal-organic complexes in solution at room temperature. ${ }^{1,8,33}$

${ }^{b}$ The $\mathrm{S}_{0}$ Raman peak frequencies (in $\mathrm{cm}^{-1}$ unit) of $5 \mathrm{mM} \mathrm{W}(\mathrm{CO})_{6}, \mathrm{Bi}-\mathrm{W}$, and $\mathrm{W}(\mathrm{CO})_{5}-\left(\mathrm{OHCH}_{3}\right)$ complexes in $\mathrm{MeOH}$ as determined by GS-FSRS experiments (see Figure 2 in main text).

${ }^{c}$ Vibrational normal mode frequencies of $\mathrm{W}(\mathrm{CO})_{6}, \mathrm{Bi}-\mathrm{W}$, and $\mathrm{W}(\mathrm{CO})_{5}-\left(\mathrm{OHCH}_{3}\right)$ in $\mathrm{MeOH}$ were calculated from the geometrically optimized structure in the electronic ground state $\left(\mathrm{S}_{0}\right)$ using Gaussian software (Section "Quantum calculations" above) and a frequency scaling factor of $1 .{ }^{8}$ ${ }^{d}$ The calculated bond lengths for $\mathrm{W}-\mathrm{L}($ trans $)\left(\mathrm{L}=\mathrm{CO}, \mathrm{Bi}(\mathrm{Ph})_{3}\right.$, and $\left.\mathrm{OHCH}_{3}\right)$ and $\mathrm{W}-\mathrm{CO}$ (axial) are summarized in Table S2 below. Figure S4 shows the role of the trans ligand in W-CO (axial) $\pi$-backbonding from quantum calculations. The weak $\sigma$-bonding between $\mathrm{W}-\mathrm{L}\left(\mathrm{L}=\mathrm{Bi}(\mathrm{Ph})_{3}\right.$ and $\mathrm{OHCH}_{3}$, bulkier than $\mathrm{CO}$ ) results in a relatively large bond length, which may explain the absence of significant $\mathrm{Bi}-\mathrm{W}$ and $\mathrm{W}-\mathrm{O}$ stretching motions. In addition, the $\mathrm{Bi}-\mathrm{W}$ bimetallic bond stretching mode $\left(<200 \mathrm{~cm}^{-1}\right)$ is outside of our detection spectral window (see main text).

${ }^{e}$ The calculation was performed with an explicit $\mathrm{Bi}(\mathrm{Ph})_{3}$ ligand nearby the photoproduct. The interatomic distance between the two metal centers in the optimized structure is $6.60261 \AA$.

${ }^{f}$ The plane is defined by the four (equatorial) CO groups. See Figure 2a inset for illustration. ${ }^{g}$ Totally symmetric $\left(\mathrm{A}_{1 \mathrm{~g}}\right)$ vibrations from the parent $\mathrm{W}(\mathrm{CO})_{6}$ molecule with $O_{h}$ symmetry. The symmetry reduction in $\mathrm{W}-\mathrm{L}\left(\mathrm{L}=\mathrm{Bi}(\mathrm{Ph})_{3}\right.$ and $\left.\mathrm{OHCH}_{3}\right)$ accounts for the differing vibrational motions listed in Table S1 (see N/A).

${ }^{h}$ For these two Ph-specific modes, calculation results for the reactant $\mathrm{Bi}-\mathrm{W}$ are contrasted with the photoproduct species that involve $\mathrm{W}(\mathrm{CO})_{5}-\left(\mathrm{OHCH}_{3}\right)$ and an adjacent $\mathrm{Bi}(\mathrm{Ph})_{3}$ (right columns).

${ }^{i}$ These atomic motions involve the axial CO stretch, and a vibrational mode blueshift $(1983 \rightarrow 2030$ $\left.\mathrm{cm}^{-1}\right)$ is associated with symmetry reduction from tungsten hexacarbonyl to pentacarbonyl species. 
Table S2. Selected bond lengths for $\mathrm{W}(\mathrm{CO})_{5}-\mathrm{Bi}(\mathrm{Ph})_{3}$ determined by $\mathrm{X}$-ray crystal structure and DFT calculations with $\omega$ B97X-D and B3LYP functionals

\begin{tabular}{|c|c|c|c|}
\hline \multirow{2}{*}{ Parameters } & \multicolumn{3}{|c|}{$\mathbf{W}(\mathbf{C O})_{5}-\mathbf{B i}(\mathbf{P h})_{\mathbf{3}}$} \\
\cline { 2 - 4 } & X-ray structure $(\AA)$ & $\omega \mathrm{B} 97 \mathrm{X}-\mathrm{D}(\AA)$ & $\mathrm{B} 3 \mathrm{LYP}(\AA)$ \\
\hline $\mathrm{Bi}-\mathrm{W}$ & $2.8294(5)$ & 2.83262 & 2.91627 \\
\hline $\mathrm{Bi}-\mathrm{C}$ & $2.217(9)-2.234(9)$ & $2.19331-2.19469$ & $2.22226-2.22298$ \\
\hline $\mathrm{C}=\mathrm{C}$ (phenyl) & $1.356(17)-1.401(14)$ & $1.39305-1.39801$ & $1.39680-1.40239$ \\
\hline $\mathrm{W}-\mathrm{C}^{a}$ & $1.984(10)-2.065(12)$ & $1.99046-2.04884$ & $1.99291-2.05735$ \\
\hline $\mathrm{C}-\mathrm{O}$ & $1.131(13)-1.159(13)$ & $1.15056-1.15684$ & $1.15553-1.16213$ \\
\hline
\end{tabular}

${ }^{a}$ The $\mathrm{W}-\mathrm{C}$ bond length along the axial direction is the shortest $(1.984 \AA)$ in comparison with the largely equivalent $\mathrm{W}-\mathrm{C}$ bond lengths in the equatorial plane $(2.018,2.050,2.057,2.065 \AA) .{ }^{1}$ This trend is in accord with the calculation results.

The DFT calculations for $\mathrm{W}(\mathrm{CO})_{5}-\mathrm{Bi}(\mathrm{Ph})_{3}$ modeled bulk solvent using the IEFPCM method without explicit solvent molecules that exert more directional and specific interactions at a close distance (see Section "Quantum calculations" above), which may affect the results for the selected bond lengths when compared to the X-ray crystal structure. ${ }^{1}$ However, the calculated trends are consistent with the $\omega \mathrm{B} 97 \mathrm{X}-\mathrm{D}$ functional having shorter bond lengths than the overestimating B3LYP functional in metal-carbonyl complexes. ${ }^{15}$ This point is especially apparent in the bimetallic $\mathrm{Bi}-\mathrm{W}$ bond, so we adopted the $\omega \mathrm{B} 97 \mathrm{X}-\mathrm{D}$ functional and the Genecp mixed basis sets for DFT calculations (see the results in Table S1). 
Table S3. Calculated bond lengths for $\mathrm{W}-\mathrm{L}$ (trans) $\left(\mathrm{L}=\mathrm{CO}, \mathrm{Bi}(\mathrm{Ph})_{3}\right.$, and $\left.\mathrm{OHCH}_{3}\right)$ and $\mathrm{W}-\mathrm{CO}$ (axial) in the tungsten carbonyl complex

\begin{tabular}{|c|c|c|c|}
\hline \multirow{2}{*}{ Parameters } & \multicolumn{3}{|c|}{ Ligand (L) } \\
\cline { 2 - 4 } & $-\mathbf{C O}(\AA)$ & $-\mathbf{B i}(\mathbf{P h})_{\mathbf{3}}(\AA)$ & $-\mathbf{O H C H}_{\mathbf{3}}(\AA)$ \\
\hline W-L (trans) & 2.06 & 2.83 & 2.28 \\
\hline W-CO (axial) & 2.06 & 1.99 & 1.97 \\
\hline
\end{tabular}

Deviations in the $\mathrm{W}-\mathrm{L}\left(\right.$ trans) and $\mathrm{W}-\mathrm{CO}$ (axial) bond lengths from the parent $\mathrm{W}(\mathrm{CO})_{6}$ molecule $(\mathrm{L}=\mathrm{CO})$ are mainly due to the $\sigma$-donating capabilities of the trans ligand. The relatively long $\mathrm{Bi}-\mathrm{W}$ bond is a result of $\sigma$-donating/ $\pi$-accepting property ${ }^{34}$ and bulkiness of the $\mathrm{Ph}_{3} \mathrm{Bi}$ ligand. The stronger $\sigma$-donating property of this ligand corroborates a shorter $\mathrm{W}-\mathrm{CO}$ (axial) bond length since the electron density on the metal center is increased when compared to the parent molecule. ${ }^{1}$ Notably, the $\mathrm{W}-\mathrm{OHCH}_{3}$ bond length is shorter than the corresponding $\mathrm{W}-\mathrm{L}$ bond length with the $\mathrm{Ph}_{3} \mathrm{Bi}$ ligand, albeit longer than that with the $\mathrm{CO}$ ligand (hence sterics and symmetry of the trans ligand also contribute to the bond order). Since $\mathrm{MeOH}$ is the strongest $\sigma$-donating ligand of the three ligands (Figure S4), it makes sense that this bond length is shorter than the bimetallic bond. Meanwhile, the associated $\mathrm{W}-\mathrm{CO}$ (axial) bond is the shortest, due to a greater amount of electron density on the metal center and the increased amount of $\pi$-backbonding into the CO $\pi^{*}$ orbital. ${ }^{16}$

Moreover, the absorption spectrum of $\mathrm{W}(\mathrm{CO})_{5}-\left(\mathrm{OHCH}_{2} \mathrm{CH}_{3}\right)$ was also computed using the TD-DFT energy calculation at the optimized geometry of the electronic ground state using the same functional and basis sets (see "Quantum calculations" section above). A small blueshift of the $\sim 415 \mathrm{~nm}$ peak in $\mathrm{MeOH}$ was predicted at $\sim 413 \mathrm{~nm}$ in EtOH, largely matching the observed trend in Figure 1b,c (main text). Notably, the calculated absorption band in the visible region is dramatically diminished in the $\mathrm{Bi}-\mathrm{W}$ complex, which shows much more intense absorption bands in the UV region (Figure S2) and corroborates the observed absorption spectral change (Figure 1). 


\section{$\underline{\text { SI References }}$}

(1) Holmes, N. J.; Levason, W.; Webster, M. Triphenylbismuthine Complexes of Group 6 Metal Carbonyls: X-ray Crystal Structures of $\left[\mathrm{M}(\mathrm{CO})_{5}\left(\mathrm{BiPh}_{3}\right)\right](\mathrm{M}=\mathrm{Mo}$ or W). J. Organomet. Chem. 1997, 545-546, 111-115.

(2) Saha, S.; Keszler, D. A. Synthesis of Bimetallic Tin-Tungsten and Bismuth-Tungsten Carbonyl Complexes for the Precursor of Thin Oxide Films. In American Chemical Society National Meeting, San Francisco, CA, 2014.

(3) Liu, W.; Han, F.; Smith, C.; Fang, C. Ultrafast Conformational Dynamics of Pyranine during Excited State Proton Transfer in Aqueous Solution Revealed by Femtosecond Stimulated Raman Spectroscopy. J. Phys. Chem. B 2012, 116, 10535-10550.

(4) Tang, L.; Zhu, L.; Taylor, M. A.; Wang, Y.; Remington, S. J.; Fang, C. Excited State Structural Evolution of a GFP Single-Site Mutant Tracked by Tunable Femtosecond-Stimulated Raman Spectroscopy. Molecules 2018, 23, 2226.

(5) Zhu, L.; Liu, W.; Fang, C. A Versatile Femtosecond Stimulated Raman Spectroscopy Setup with Tunable Pulses in the Visible to Near Infrared. Appl. Phys. Lett. 2014, 105, 041106.

(6) Liu, W.; Wang, Y.; Tang, L.; Oscar, B. G.; Zhu, L.; Fang, C. Panoramic Portrait of Primary Molecular Events Preceding Excited State Proton Transfer in Water. Chem. Sci. 2016, 7, 54845494.

(7) Fang, C.; Tang, L.; Oscar, B. G.; Chen, C. Capturing Structural Snapshots during Photochemical Reactions with Ultrafast Raman Spectroscopy: From Materials Transformation to Biosensor Responses. J. Phys. Chem. Lett. 2018, 9, 3253-3263. 
(8) Zhu, L.; Saha, S.; Wang, Y.; Keszler, D. A.; Fang, C. Monitoring Photochemical Reaction Pathways of Tungsten Hexacarbonyl in Solution from Femtoseconds to Minutes. J. Phys. Chem. $B$ 2016, 120, 13161-13168.

(9) Frisch, M. J.; Trucks, G. W.; Schlegel, H. B.; Scuseria, G. E.; Robb, M. A.; Cheeseman, J. R.; Scalmani, G.; Barone, V.; Mennucci, B.; Petersson, G. A.; et al. Gaussian 09, Revision B.1; Gaussian, Inc.: Wallingford, CT, 2009.

(10) Tang, L.; Zhu, L.; Ener, M. E.; Gao, H.; Wang, Y.; Groves, J. T.; Spiro, T. G.; Fang, C. Photoinduced Charge Flow Inside an Iron Porphyrazine Complex. Chem. Commun. 2019, 55, 13606-13609.

(11) Scott, A. P.; Radom, L. Harmonic Vibrational Frequencies: An Evaluation of Hartree-Fock, Møller-Plesset, Quadratic Configuration Interaction, Density Functional Theory, and Semiempirical Scale Factors. J. Phys. Chem. 1996, 100, 16502-16513.

(12) Computational Chemistry Comparison and Benchmark DataBase, Release 20 (August 2019) Standard Reference Database 101 (https://cccbdb.nist.gov/vsfx.asp). In Vibrational frequency scaling factors; National Institute of Standards and Technology, 2019.

(13) Chai, J.-D.; Head-Gordon, M. Systematic Optimization of Long-Range Corrected Hybrid Density Functionals. J. Chem. Phys. 2008, 128, 084106.

(14) Lisac, K.; Topić, F.; Arhangelskis, M.; Cepić, S.; Julien, P. A.; Nickels, C. W.; Morris, A. J.; Friščić, T.; Cinčić, D. Halogen-Bonded Cocrystallization with Phosphorus, Arsenic and Antimony Acceptors. Nat. Commun. 2019, 10, 61.

(15) Mendes, M.; Regeta, K.; Ferreira da Silva, F.; Jones, N. C.; Hoffmann, S. V.; García, G.; Daniel, C.; Limão-Vieira, P. Comprehensive Investigation of the Electronic Excitation of W(CO) 6 
by Photoabsorption and Theoretical Analysis in the Energy Region from 3.9 to $10.8 \mathrm{eV}$. Beilstein J. Nanotechnol. 2017, 8, 2208-2218.

(16) Wrighton, M. The Photochemistry of Metal Carbonyls. Chem. Rev. 1974, 74, 401-430.

(17) Dahlgren, R. M.; Zink, J. I. Ligand Substitution Photochemistry of Monosubstituted Derivatives of Tungsten Hexacarbonyl. Inorg. Chem. 1977, 16, 3154-3161.

(18) Schadt, M. J.; Gresalfi, N. J.; Lees, A. J. Characterization and Reaction Kinetics of Intermediates Produced in the Photolysis of $\mathrm{M}(\mathrm{CO})_{6}(\mathrm{M}=\mathrm{Cr}$, Mo, W) Solutions Containing a 1,4-diazabutadiene Ligand. Inorg. Chem. 1985, 24, 2942-2946.

(19) Joly, A. G.; Nelson, K. A. Metal Carbonyl Photochemistry in Organic Solvents: Femtosecond Transient Absorption and Preliminary Resonance Raman Spectroscopy. Chem. Phys. 1991, 152, 69-82.

(20) Meyer, T. J.; Caspar, J. V. Photochemistry of Metal-Metal Bonds. Chem. Rev. 1985, 85, $187-218$.

(21) Zhang, J. Z.; Harris, C. B. Photodissociation Dynamics of $\mathrm{Mn}_{2}(\mathrm{CO})_{10}$ in Solution on Ultrafast Time Scales. J. Chem. Phys. 1991, 95, 4024-4032.

(22) Chen, J.; Zhang, H.; Tomov, I. V.; Ding, X.; Rentzepis, P. M. Photochemistry and Electrontransfer Mechanism of Transition Metal Oxalato Complexes Excited in the Charge Transfer Band. Proc. Natl. Acad. Sci. U. S. A. 2008, 105, 15235-15240.

(23) Zhu, L.; Saha, S.; Liu, W.; Wang, Y.; Keszler, D. A.; Fang, C. Simultaneous Solution-based Generation and Characterization of Crystalline Bismuth Thin Film by Femtosecond Laser Spectroscopy. Appl. Phys. Lett. 2015, 107, 061901. 
(24) Joly, A. G.; Nelson, K. A. Femtosecond Transient Absorption Spectroscopy of Chromium Hexacarbonyl in Methanol: Observation of Initial Excited States and Carbon Monoxide Dissociation. J. Phys. Chem. 1989, 93, 2876-2878.

(25) Wang, L.; Zhu, X.; Spears, K. G. Reactions of Naked Chromium Pentacarbonyl in Tetrahydrofuran Solution Observed by Picosecond Infrared Transient Absorption. J. Phys. Chem. 1989, $93,2-4$.

(26) Xie, X.; Simon, J. D. Picosecond Time Resolved Absorption Studies of the Solvation of $\mathrm{Cr}(\mathrm{CO})_{5}$ in Alcohols: A Unimolecular Kinetic Model for the Formation of $\mathrm{Cr}(\mathrm{CO})_{5}(\mathrm{OHR})$ from Photogenerated $\mathrm{Cr}(\mathrm{CO})_{5}(\mathrm{ROH})$. J. Am. Chem. Soc. 1990, 112, 1130-1136.

(27) Shanoski, J. E.; Glascoe, E. A.; Harris, C. B. Ligand Rearrangement Reactions of $\mathrm{Cr}(\mathrm{CO})_{6}$ in Alcohol Solutions: Experiment and Theory. J. Phys. Chem. B 2006, 110, 996-1005.

(28) Simon, J. D. Time-Resolved Studies of Solvation in Polar Media. Acc. Chem. Res. 1988, 21, 128-134.

(29) Agmon, N.; Huppert, D.; Masad, A.; Pines, E. Excited-State Proton Transfer to MethanolWater Mixtures. J. Phys. Chem. 1991, 95, 10407-10413.

(30) Horng, M. L.; Gardecki, J. A.; Papazyan, A.; Maroncelli, M. Subpicosecond Measurements of Polar Solvation Dynamics: Coumarin 153 Revisited. J. Phys. Chem. 1995, 99, 17311-17337.

(31) Simon, J. D.; Xie, X. Photodissociation of Chromium Hexacarbonyl in Solution: Direct Observation of the Formation of Pentacarbonyl(methanol)chromium. J. Phys. Chem. 1986, 90, 6751-6753.

(32) Lian, T.; Bromberg, S. E.; Asplund, M. C.; Yang, H.; Harris, C. B. Femtosecond Infrared Studies of the Dissociation and Dynamics of Transition Metal Carbonyls in Solution. J. Phys. Chem. 1996, 100, 11994-12001. 
(33) Kosma, K.; Trushin, S. A.; Fuß, W.; Schmid, W. E.; Schneider, B. M. R. Photodissociation

of Group-6 Hexacarbonyls: Observation of Coherent Oscillations in an Antisymmetric (Pseudorotation) Vibration in $\mathrm{Mo}(\mathrm{CO})_{5}$ and $\mathrm{W}(\mathrm{CO})_{5}$. Phys. Chem. Chem. Phys. 2010, 12, 1319713214.

(34) Mitoraj, M. P.; Michalak, A. $\sigma$-Donor and $\pi$-Acceptor Properties of Phosphorus Ligands: An Insight from the Natural Orbitals for Chemical Valence. Inorg. Chem. 2010, 49, 578-582.

\section{Full Authorship for the Gaussian 09 (Revision B.1) Software:}

Frisch, M. J.; Trucks, G. W.; Schlegel, H. B.; Scuseria, G. E.; Robb, M. A.; Cheeseman, J. R.; Scalmani, G.; Barone, V.; Mennucci, B.; Petersson, G. A.; Nakatsuji, H.; Caricato, M.; Li, X.; Hratchian, H. P.; Izmaylov, A. F.; Bloino, J.; Zheng, G.; Sonnenberg, J. L.; Hada, M.; Ehara, M.; Toyota, K.; Fukuda, R.; Hasegawa, J.; Ishida, M.; Nakajima, T.; Honda, Y.; Kitao, O.; Nakai, H.; Vreven, T.; J. A. Montgomery, J.; Peralta, J. E.; Ogliaro, F.; Bearpark, M.; Heyd, J. J.; Brothers, E.; Kudin, K. N.; Staroverov, V. N.; Kobayashi, R.; Normand, J.; Raghavachari, K.; Rendell, A.; Burant, J. C.; Iyengar, S. S.; Tomasi, J.; Cossi, M.; Rega, N.; Millam, J. M.; Klene, M.; Knox, J. E.; Cross, J. B.; Bakken, V.; Adamo, C.; Jaramillo, J.; Gomperts, R.; Stratmann, R. E.; Yazyev, O.; Austin, A. J.; Cammi, R.; Pomelli, C.; Ochterski, J. W.; Martin, R. L.; Morokuma, K.; Zakrzewski, V. G.; Voth, G. A.; Salvador, P.; Dannenberg, J. J.; Dapprich, S.; Daniels, A. D.; Farkas, Ö.; Foresman, J. B.; Ortiz, J. V.; Cioslowski, J.; Fox, D. J. 